\title{
Psychiatric Disorders and Amphetamine Dependency - A Comparative-Analytical Study
}

\author{
Seyyed Mohammad Moosavi ${ }^{1}$, Mahshid Ahmadi ${ }^{2}$, Mani B. Monajemi ${ }^{3}$, , Jamshid Yazdani ${ }^{4}$ \\ ${ }^{1}$ Department of Psychiatry, Mazandaran University of Medical Sciences, Sari, Iran \\ ${ }^{2}$ Department of Social Medicine, Mazandaran University of Medical Sciences, Sari, Iran \\ ${ }^{3}$ Department of Clinical Psychology, University of Tehran, Tehran, Iran \\ ${ }^{4}$ Department of Statistics, Mazandaran University of Medical Sciences, Sari, Iran
}

Email address:

mani.b.monajemi@warwickgrad.net (M. B. Monajemi), mani.b.monajemi@ut.ac.ir (M. B. Monajemi)

\section{To cite this article:}

Seyyed Mohammad Moosavi, Mahshid Ahmadi, Mani B. Monajemi, Jamshid Yazdani. Psychiatric Disorders and Amphetamine Dependency A Comparative-Analytical Study. American Journal of Psychiatry and Neuroscience. Vol. 3, No. 6, 2015, pp. 104-107.

doi: 10.11648/j.ajpn.20150306.11

\begin{abstract}
Objective: With respect to prevalence of amphetamine dependency and its uprising trend comparing to other substances and due to lack of studies in this field; this study was conducted. Materials and Methods: This comparativeanalytical study was conducted between 2012-2014 in a psychiatric Hospital (Sari, Iran) in order to assess the correlation between psychiatric disorders and amphetamine (Ice and Crystal) dependency. One hundred men between 20-50 years old with dependency (case group) and one hundred men with no history of amphetamine dependency (control group) were selected. Data obtained through structured psychiatric interview and anonymous demographic questionnaire and analyzed via Chi-Square and SPSS19. Results: Mean age of case group was noticeably lower than control. Meaningful differences between case and control groups were observed with respect to type of psychiatric disorders. Difference in educational level between two groups was meaningful. [Case-group had lower levels of education $(\mathrm{p}<0.01)$ ]. Discussion: A lot of studies have been conducted regarding substance dependency but most of them are about opioids and few studies have been conducted regarding amphetamine spectrum substances such as Ice and Crystal. Among studies which have been conducted in area of Amphetamine dependency, most of them have focused on psychosis solely or psychiatric symptoms such as Anhedonia. Novel point of this study is that it focuses on wider range of psychiatric disorders with notifying factors such as educational level, age, gender and marital status.
\end{abstract}

Keywords: Amphetamine Dependency, Psychiatric Disorders

\section{Introduction}

For hundred years opium and opioids have been used but in recent years amphetamine use has emerged as an epidemic health concern among substance users. The increasing rate may be due to socio-economic changes and psychological pressures. Several studies in the field of drug dependency have been done but the majority of researches are in the area of opioids. On the other side, many studies about amphetamines remain descriptive and also amphetamine use is considerable health problem thereby, there is still a need to conduct analytical studies. This study was conducted to assessing the correlation of psychiatric disorders and amphetamine dependency.

Use of amphetamine and amphetamine- like is widespread in the general population and common among patients with psychiatric disorders. Amphetamines may induce symptoms of psychosis very similar to those of acute schizophrenia spectrum psychosis. To distinguish the two types of psychosis on the basis of acute symptoms is difficult. [1] The rapidly growing popularity of amphetamine use in has posed a new health challenge to the health sector. Although amphetamine use is considerable health problems but there is still a need to conduct epidemiological studies on the prevalence and its health related problems. The present paper emphasizes that health policy makers should consider the immediate needs of drug users, their families and the community to be informed about the detrimental health effects associated with amphetamine. [2] Amphetamine was discovered over 100 years ago. Amphetamine dependence is a public health problem with medical, psychiatric, cognitive, legal and socioeconomic consequences. [3-4] Amphetamine or 
amphetamine-type stimulants are the second most frequently used illicit drug worldwide, second only to cannabis. [5] Use of these stimulants has significant psychiatric and medical consequences, including psychosis, dependence, overdose, Parkinson disease and death. Amphetamine abuse and dependency in particular is an extremely serious and growing problem in many countries. [6-7] Amphetamine ('Speed') and methamphetamine ('Ice') are illicit drugs abused for their euphoric effects. [8] Even temporary use of these drugs are associated with impulsivity, anxiety, depression and mania [9-12] and recurrent admissions. [13]. There is not sill enough comparative researches in relation with amphetamine in contrast of raising the prevalence of abuse and dependency. The aim of this study was to clear relatively vague sides in this field.

\section{Materials and Methods}

This comparative - analytical study was conducted between 2012-2014 in psychiatric Hospital (Sari, Iran) in order to assess the correlation between psychiatric disorders and amphetamine dependency. In this study, two hundred men between 20-50 who referred to a psychiatric Hospital for the first time were chosen. 100 of them who were Amphetamine dependent considered as case group and 100 of who didn't have Amphetamine dependency considered as control group. Sample size was estimated $21 \%$ regarding the prevalence rate of psychiatric disorders in general population that was evaluated between $14-28 \%$ in previous studies [17].

One hundred men between 20-50 years old, who were referred to psychiatric clinic and had a history of amphetamine dependency for 1-5 years and they didn't report any kind of other substances abuse in last year except amphetamine were selected as case group. Amphetamine dependency reported by the own patient or his family; In order to confirm the diagnosis psychiatric interview was conducted based on DSM-4-R and urine test was done to re-confirm. One hundred men with no history of amphetamine dependency according to self or family report who referred to the psychiatric Hospital for the first time were selected as control group and they also went through structured psychiatric interview and anonymous demographic questionnaire. Sampling was done via convenience sampling method. All the individual in case group were informed about the study and consent form was signed by him or his first-degree family member (If a patient was in acute psychotic episode). One hundred male patients between 20-50 years old who had referred to psychiatric Hospital for the first time and didn't have amphetamine dependency based on self/family report and psychiatric interview and also negative urine test, were chosen as control group. Informing the patients about the study and signing the consent forms was done in this group too. Sampling continued till sample size reached to 100 for each group. Exclusion criteria in control group were: previous/current use of Amphetamines, mental retardation, or obvious somatic disorders. If the psychiatrist had suspicion of mental retardation, adult raven intelligence test employed for assessing this hunch. In patients in both groups that the diagnosis of disorder in axis 1 was not established, Minnesota Multiple Personality Inventory (MMPI) was done for reassurance. John C-Raven made raven IQ test. It includes 60 visual questions and based on the results it can divide the examinees into 7 categories. In this test, scores lower than 70 considered being mental retardation [18]. MMPI is a self-report questionnaire that was designed by Starke R. Hathaway and J. C. McKinley in 1987. The answers are: Correct/Incorrect or I can't answer. MMPI will generate results in 10 clinical scales [19]. Ice and crystal considered as amphetamine substances in this study. Data regarding comorbidity of Amphetamine substance abuse and other psychiatric disorders were analyzed with Chi-Square test, logistic regression and Spss19 software. In this study, meaningfulness degree considered 0.05 .

\section{Results}

Mean age of case group was 28.2 \pm 6.55 and $32.8 \pm 7.57$ for control group. Significant differences was seen between two groups $(\mathrm{P}<0.01)$. Mean age of control group was higher than case group.

In this study, individuals were divided into four groups: under 25, 26-30, 31-40 and more. Significant differences were noticed in each age range between two groups (Table No1).

$56 \%$ of Amphetamine dependent individuals were single and $44 \%$ were married and $46 \%$ were single and $54 \%$ were married in control group. No significant differences regarding marital status was mentioned between two groups (Table No2).

Regarding educational level, non-Amphetamine dependent individuals were more educated than amphetamine dependent patients. (TableNo3).

In assessing samples, Psychosis had the most prevalence between people with diploma degree or lower, while in bachelor level degree or higher, the highest prevalence was related to depression (Table No4).

Duration of Amphetamine abuse in dependent individuals was between 1-5 years with mean dependent duration of $2.25 \pm 1.1$. Mean usage period of individuals with various disorders is depicted in Table No4. Comparing psychological disorders of both groups and comparing both groups in terms of frequency of psychiatric disorders has been illustrated in table No5 and table No6 and the differences were meaningful.

Table No. 1. Comparing age range of Amphetamine dependent and Non-Amphetamine dependent.

\begin{tabular}{lllll}
\hline \multirow{2}{*}{ Age Range } & \multicolumn{2}{l}{$\begin{array}{l}\text { Non-Amphetamine } \\
\text { Dependent Individuals }\end{array}$} & \multicolumn{2}{l}{$\begin{array}{l}\text { Amphetamine } \\
\text { Dependent Individuals }\end{array}$} \\
\cline { 2 - 5 } & Frequency & Percentage & Percentage & Frequency \\
\hline 25Below & 21 & 21 & 43 & 43 \\
$26-30-$ & 32 & 32 & 29 & 29 \\
$31-40$ & 26 & 26 & 23 & 23 \\
41 and older & 21 & 21 & 5 & 5 \\
\hline
\end{tabular}

Chi-square $=17.7, \mathrm{p} . \mathrm{f}=3, \mathrm{p}<0.001$ 
Table No. 2. Marital status in Amphetamine dependent and non-dependent.

\begin{tabular}{lllll}
\hline \multirow{2}{*}{ Marital status } & \multicolumn{2}{l}{\begin{tabular}{l} 
Non-Amphetamine \\
\multicolumn{2}{l}{ Dependent Individuals }
\end{tabular}} & \multicolumn{2}{l}{$\begin{array}{l}\text { Amphetamine } \\
\text { Dependent Individuals }\end{array}$} \\
\cline { 2 - 5 } & Percentage & Frequency & Percentage & Frequency \\
\hline Single & $\% 46$ & 46 & $\% 56$ & 56 \\
Married & $\% 54$ & 54 & $\% 44$ & 44 \\
\hline
\end{tabular}

Chi-square $=17.7$, p.f $=1, \mathrm{p}<0.15$

Table No. 3. Levels of education in each group.

\begin{tabular}{lllll}
\hline & Percentage & Frequency & Percentage & Frequency \\
\hline High school & $\% 27$ & 27 & $\% 39$ & 39 \\
$\begin{array}{l}\text { Diploma } \\
\text { Bachelor }\end{array}$ & $\% 45$ & 45 & $\% 46$ & 46 \\
and upper & $\% 28$ & 28 & $\% 15$ & 15 \\
\hline
\end{tabular}

Chi-square $=6.1, \mathrm{p} . \mathrm{f}=2, \mathrm{p}<0.047$

Table No. 4. Mean usage period of Amphetamine in each of disorders

\begin{tabular}{ll}
\hline Type & Mean usage period \\
\hline Depression & $2.05 \pm 0.9$ \\
Anxiety & $2.25 \pm 1.07$ \\
Psychosis & $2.29 \pm 1.1$ \\
Somatoform & $2.35 \pm 1.4$ \\
Sexual & $2.8 \pm 1.6$ \\
\hline
\end{tabular}

$\mathrm{P}=0.55, \mathrm{~F}=0.698$

Table No. 5. Prevalence rate of psychiatric disorders in different age ranges.

\begin{tabular}{|c|c|c|c|c|c|}
\hline \multirow[t]{2}{*}{$\begin{array}{l}\text { Age } \\
\text { Range }\end{array}$} & \multirow{2}{*}{$\begin{array}{l}\text { Type } \\
\text { Psychosis } \\
\end{array}$} & \multicolumn{2}{|c|}{$\begin{array}{l}\text { Non-Amphetamine } \\
\text { Dependent Individuals }\end{array}$} & \multicolumn{2}{|c|}{$\begin{array}{l}\text { Dependent } \\
\text { Amphetamine } \\
\text { Individuals }\end{array}$} \\
\hline & & Percentage & Frequency & Percentage & Frequency \\
\hline \multirow[t]{5}{*}{ Below } & Anxiety & $\% 19.0$ & 4 & $\% 53.5$ & 23 \\
\hline & Depression & $\% 28.6$ & 6 & $\% 23.3$ & 10 \\
\hline & $\begin{array}{l}\text { Sexual } \\
\text { Disorder }\end{array}$ & $\% 38.1$ & 8 & $\% 20.9$ & 9 \\
\hline & $\begin{array}{l}\text { Somatoform } \\
\text { Disorder }\end{array}$ & $\% 0$ & 0 & $\% 1$ & 1 \\
\hline & Psychosis & $\% 14.3$ & 3 & $\% 0$ & 0 \\
\hline \multirow[t]{4}{*}{$26-30$} & Anxiety & $21.9 \%$ & 7 & $65.5 \%$ & 19 \\
\hline & Depression & $25.0 \%$ & 8 & $13.8 \%$ & 4 \\
\hline & Psychosis & $43.8 \%$ & 14 & $20.7 \%$ & 6 \\
\hline & $\begin{array}{l}\text { Somatoform } \\
\text { Disorder }\end{array}$ & $9.4 \%$ & 3 & $0 \%$ & 0 \\
\hline \multirow[t]{5}{*}{$31-40$} & Psychosis & $30.8 \%$ & 8 & $39.1 \%$ & 9 \\
\hline & Anxiety & $11.5 \%$ & 3 & $21.7 \%$ & 5 \\
\hline & Depression & $34.6 \%$ & 9 & $26.1 \%$ & 6 \\
\hline & $\begin{array}{l}\text { Sexual } \\
\text { Disorder }\end{array}$ & $3.8 \%$ & 1 & $13.0 \%$ & 3 \\
\hline & $\begin{array}{l}\text { Somatoform } \\
\text { Disorder }\end{array}$ & $19.2 \%$ & 5 & $0 \%$ & 0 \\
\hline \multirow[t]{4}{*}{$\begin{array}{l}41 \text { and } \\
\text { older }\end{array}$} & Psychosis & $23.8 \%$ & 5 & $40.0 \%$ & 2 \\
\hline & Anxiety & $23.8 \%$ & 5 & $20.0 \%$ & 1 \\
\hline & Depression & $42.9 \%$ & 9 & $20.0 \%$ & 1 \\
\hline & $\begin{array}{l}\text { Sexual } \\
\text { Disorder }\end{array}$ & $9.5 \%$ & 2 & $20.0 \%$ & 1 \\
\hline
\end{tabular}

Based on Table No 5:

- In the age range of younger than 25 , there was a meaningful difference between two groups via Fisher test 11.64 and $\mathrm{p}=0.009$.
- In the age range of 26-36, there was meaningful difference between two groups via Fisher test 12.44 and $\mathrm{p}=0.004$.

- In the age range of 31-40, there no meaningful difference between two groups via Fisher test 0.142 was noticed.

- In the age range of 31-40, there no meaningful difference between two groups via Fisher test 0.142 was noticed.

In the age range of more than 41 was no meaningful difference between two groups via Fisher test 0.679 .

Table No. 6. Comparing Psychiatric disorders between Amphetamine dependent and Non-Amphetamine dependent individuals.

\begin{tabular}{lllll}
\hline Type & \multicolumn{2}{l}{$\begin{array}{l}\text { Non-Amphetamine } \\
\text { Dependent Individuals }\end{array}$} & \multicolumn{2}{l}{$\begin{array}{l}\text { Amphetamine } \\
\text { Dependent }\end{array}$} \\
& Percentage & Frequency & Percentage & Frequency \\
\hline Psychosis & $\% 24$ & 24 & $53 \%$ & 53 \\
Anxiety & $\% 22$ & 22 & $20 \%$ & 20 \\
$\begin{array}{l}\text { Depression } \\
\text { Sexual disorder }\end{array}$ & $\% 40$ & 40 & $22 \%$ & 22 \\
$\begin{array}{l}\text { Somatoform } \\
\text { disorder }\end{array}$ & $\% 11$ & 3 & $5 \%$ & 5 \\
\hline
\end{tabular}

Chi-square $=27.7$, p.f $=4, p<0.0001$

\section{Discussion}

Based on the results of this study, the average age of the case group were significantly lower than those in the control group, means that amphetamine consumption is a potential cause to a variety of psychiatric disorders and amphetamine user are vulnerable to psychiatric disorders. This vulnerability may be due to this fact that identification of prolonged and also persistent type amphetamine- induced psychosis (beside amphetamine induced psychiatric disorders in general) indicates a lasting change in the brain. Such lasting changes can be due to permanent dopamine release and inhibition dopamine reuptake by acting with dopamine transporter, thereby increasing the concentration of dopamine in synaptic cleft and also interaction with the monoamine transporter which leading to increasing amount of dopamine in cytosol alongside continual serotonergic, noradrenergic and glutaminergic neuron changes.

In this study psychiatric disorders in amphetamine dependent group were psychosis, depression and anxiety and in non- dependent patients were depression, psychosis and anxiety respectively. Majority of studies in this field have focused on the relationship between amphetamine and psychotic disorders spectrum [1, 13] and other psychiatric disorders usually neglected and also in case of assessment the effects of amphetamine, was the association of amphetamine and psychiatric symptoms such as Anhedonia ${ }^{14}$. The Novel point of this study is that it studies comprehensive range of psychiatric disorders with respect to Amphetamine dependency. According to recent similar studies with ours, amphetamine may induced symptoms of psychosis very similar to those of acute schizophrenia spectrum psychosis and to distinguish the two types of psychosis on the basis of acute symptoms is difficult, however acute psychosis induced by amphetamine seem to have a faster recovery compared to 
primary psychosis but based on the potential permanent changes which mentioned above, this recovery is not always occurs. Although the distinction between amphetamine induced- psychosis is important for understanding, we do not have clear diagnostic procedure by their symptoms ${ }^{1}$.

We found that the difference in the type of psychiatric disorders was significant and spectrum of psychotic disorders in dependent patients was much more than control group. This phenomenon may be due to direct effects of amphetamine on the brain. On the other side the same genes involved in the creation of psychosis may also associated with the vulnerability of consumption of amphetamines [7, 12].

In this study, we found significant differences regarding educational level between the two groups, means individuals with psychiatric disorders had lower education. It seems that the amphetamine dependency leads academic, educational and social dysfunction because of economic reasons and also direct effect of substance on CNS. On the other hand, psychiatric disorders (especially psychosis) start at younger age, so more dysfunction is expectable. We couldn't find any studies regarding relationship of educational level of Amphetamine dependency and educational level. Thus, this point can be considered as one of the novel points of this study.

According to the above, global efforts for prevention of dependency and treatment of dependent patients as soon as possible and awareness of the side effects of these drugs can be quite advisable.

\section{Limitations}

All subjects were male, so we could not compare both sexes.

This study focused on axis Ì disorders and we neglected personality disorders which may play a vital role in any substance abuse or dependency.

\section{Authors' Contributions}

SMM and MA conceived and designed the evaluation. MBM collected and interpreted the clinical data and drafted the manuscript. JY Participated in conducting statistical evaluation. All authors read and and approved the final manuscript.

\section{Acknowledgements}

We would like to thank all patients who participated in the study.

\section{References}

[1] Jørgen G Bramness1*, Øystein Hoel Gundersen1, Joar Guterstam2, Eline Borger Rognli1, Maija Konstenius2, Else-Marie Løberg3, Sigrid Medhus1, Lars Tanum1 and Johan Franck2. (2012). Amphetamine-induced psychosis - a separate diagnostic entity or primary psychosis triggered in the vulnerable? Available: http://www.biomedcentral.com/1471-244X/12/221/. Last accessed Sep 2015.
[2] Zahra Alam mehrjerdi1*, Alasdair M Barr2 and Alireza Noroozi3. (2013). Methamphetamine-associated psychosis: a new health challenge in Iran. Available: http://www.darujps.com/content/21/1/30. Last accessed Sep 2015.

[3] (Pérez-Mañá C1, Castells X, Torrens M, Capellà D, Farre M. (2013). Efficacy of psychostimulant drugs for amphetamine abuse or dependence.. Available: http://www.ncbi.nlm.nih.gov/pubmed/23996457. Last accessed Sep 2015.

[4] Heal DJ1, Smith SL, Gosden J, Nutt DJ.. (2013). Amphetamine, past and present--a pharmacological and clinical perspective. Available: http://www.ncbi.nlm.nih.gov/pubmed/23539642. Last accessed sep 2015.

[5] Brensilver M1, Heinzerling KG, Shoptaw S.. (2013). Pharmacotherapy of amphetamine-type stimulant dependence: an update.. $\quad$ Available: http://www.ncbi.nlm.nih.gov/pubmed/23617468. Last accessed Sep 2015.

[6] Chen H(1), Wu J, Zhang J, Hashimoto K.Health, JapanCurr Drug Abuse Rev. 2010 Dec;3(4):222-38.

[7] Suzana Gispert,1 Filomena Ricciardi,1 Alexander Kurz,1 Mekhman Azizov,1 Hans-Hermann Hoepken,1 Dorothea Becker,2 Wolfgang Voos,2 Kristina Leuner,3 Walter E. Müller,3 Alexei P. Kudin,4 Wolfram S. Kunz,. (2009). Parkinson Phenotype in Aged PINK1-Deficient Mice Is Accompanied by Progressive Mitochondrial Dysfunction in Absence of Neurodegeneration. Available: http://www.ncbi.nlm.nih.gov/pmc/articles/PMC2686165/. Last accessed Sep 2015.

[8] Steinkellner T1, Freissmuth M, Sitte HH, Montgomery T.. (2011). The ugly side of amphetamines: short- and long-term toxicity of 3,4-methylenedioxymethamphetamine (MDMA, 'Ecstasy'), methamphetamine and D-amphetamine.. Available: http://www.ncbi.nlm.nih.gov/pubmed/21194370. Last accessed Sep 2015.

[9] Lester D, Yang B, Spinella M. Depression, Anxiety and personal finance behavior: Implications for the classical economic conception of humans as rational decision-makers. Physicol Rep 2006; 99(3): 833-4.

[10] Kiss E, Piko B, Vetro A. Frequency of smoking, drinking and substance use and their relationship to psychiatric comorbidity in depressed child and adolescent population. Psychiatr Hung 2006; 21(5): 371-8.

[11] Pavarin RM. Substance use and Related Problems: A Study on the Abuse of Recreational and not Recreational Drugs in Northern Italy. Ann 1st super sanita 2.

[12] SegalDS, WeinbergeSBr, Cahili J, Mccunney SJ. Multiple Daily Amphetamine Administration: Behavioral and Neurochemical Alternations. Am J psych. 2007; 207: 904-7.

[13] Sara G, Burgess P, Malhi G, Whiteford H. Amphetamine availability and admissions for psychosis in new South Wales. AUSNZ J Psychiatr. 2011 AP; 45(4): 317 -24006; 42(4):477-84.

[14] Adam M. Leventhal, Molly Brightman, Katherine J. Ameringer, Jodie Greenberg, Lavonda Mickens, Lara A. Ray, Ping Sun, and Steve Sussman. (2012). Anhedonia Associated With Stimulant Use and Dependence in a Population-Based Sample of American Adults. Available: http://www.ncbi.nlm.nih.gov/pmc/articles/PMC3307593/. Last accessed Sep 2015. doi: 10.1037/a0021964. 